\title{
Predictors of the therapeutic effect of sivelestat in patients with acute lung injury associated with systemic inflammatory response syndrome
}

\author{
Takuma Ozawa $^{1}$, Kiyoshi Mihara ${ }^{2 *}$ and Nobuhiro Yasuno ${ }^{1}$
}

\begin{abstract}
Background: Sivelestat, a neutrophil elastase inhibitor, was previously approved in Japan for the treatment of acute lung injury associated with systemic inflammatory response syndrome. However, sivelestat produced inconsistent therapeutic benefits. This study aimed to identify factors predicting the therapeutic effects of sivelestat.

Methods: We enrolled 53 mechanically ventilated patients who received sivelestat. The patients were classified as effective $(n=28)$ if they were weaned from the ventilator within 28 days, or as ineffective groups $(n=25)$. Patient characteristics were compared between these groups and multivariate logistic regression analysis was used to identify predictive factors. A validation study was then conducted in sivelestat-free patients.

Results: A high red blood cell count and low hydrogen ion concentration were significantly associated with a higher ventilator weaning rate in patients receiving sivelestat. The validation study revealed that the hydrogen ion concentration value also significantly associated with ventilator weaning in patients who did not receive sivelestat.

Conclusions: Although hydrogen ion concentration was inversely associated with the ventilator weaning rate, it did not predict sivelestat efficacy. This study indicated that acute lung injury patients with a high red blood cell count would derive the most benefit from sivelestat administration.
\end{abstract}

Keywords: Sivelestat, Acute lung injury, Efficacy prediction, Logistic regression analysis, Red blood cell

\section{Background}

Acute lung injury (ALI) is a complex disorder caused by inflammation in response to conditions such as pneumonia and sepsis. ALI is characterized by a neutrophilic inflammatory response, associated with increased pulmonary vascular permeability [1]. Neutrophil elastase (NE) is one of the proteases released from the neutrophils that accumulate in the lung [2]. It degrades lung connective tissues and enhances lung vasopermeability, resulting in ALI. Furthermore, NE increases the production of neutrophil migration factor and is recognized as an important driver of systemic inflammatory response syndrome (SIRS) [3].

\footnotetext{
*Correspondence: k_mihara@musashino-u.ac.jp

${ }^{2}$ Research Center for Clinical Pharmacy, Faculty of Pharmacy, Musashino University, 1-1-20 Shinmachi, Nishitokyo-shi, Tokyo 202-8585, Japan Full list of author information is available at the end of the article
}

Sivelestat is a selective NE inhibitor, which binds directly to NE and inactivates it by a reversible acylationdeacylation mechanism [4-6]. In addition, it relaxes vascular smooth muscle [7]. Sivelestat was approved in Japan as a therapeutic drug for ALI associated with SIRS, but is also used in other situations. For example, perioperative administration of sivelestat for esophagectomy improves postoperative respiratory function and shortens the duration of hospitalization and of mechanical ventilation [8-12]. Moreover, sivelestat is administered for pediatric cardiopulmonary bypass surgery because it attenuates the perioperative inflammatory response [13]. Sivelestat also shortens the duration of mechanical ventilation, intensive care unit stay, and hospitalization due to severe respiratory failure after thoracic aortic surgery [14].

In a post-marketing clinical trial (phase IV) conducted in Japan [4], the adjusted mean number of ventilator- 
free days (VFD) was significantly higher in the sivelestat group than in the control group $(P=0.0022)$. However, the Sivelestat Trial in ALI Patients Requiring Mechanical Ventilation (STRIVE) study [15] did not identify a significant increase in VFDs in the sivelestat group, as compared with the control group, and the final analysis revealed no effect of sivelestat on VFD (day 1-28). Furthermore, the 180-day all-cause mortality was higher in the sivelestat group than in the control group $(P=0.006)$. This resulted in the discontinuation of this clinical trial and sivelestat thus failed to receive approval in other countries, such as the USA.

These trials $[4,15]$ found that the efficacy of sivelestat was inconsistent and it would therefore be beneficial to identify the factors determining the differential effects of sivelestat in patients who respond to treatment, versus the non-responders. The purpose of this case-control study was to identify factors predicting the therapeutic effects of sivelestat.

\section{Methods \\ Patients}

The case-control study was conducted in compliance with the Strengthening the Reporting of Observational Studies in Epidemiology statement and the Declaration of Helsinki. The protocol (H024-003) was approved by the institutional review board at Kan-etsu hospital (Saitama, Japan). Fifty-three patients on mechanical ventilation, who were administered sivelestat in the hospital from April 2006 to March 2012, were enrolled in this study.

\section{Study design}

The patients were divided into two groups, according to whether they were categorized as effective or ineffective. Patients in the effective group were weaned from the ventilator within 28 days. VFDs (the primary endpoint of the phase IV study in Japan [14]) and all-cause mortality (the primary endpoint of the STRIVE study [15]) were both assessed within 28 days in these studies; we therefore used a 28-day monitoring period in the present study.

Data from the day before sivelestat administration were used for this analysis. If these were unavailable, we used the data from two days before sivelestat administration or from the day of sivelestat administration. Vital signs and $\mathrm{SpO}_{2}$ were not included in the analysis because they were affected by concomitant drugs or ventilation. We initially compared the effective and ineffection group data. We subsequently identified predictive factors using the multivariate analysis described below.

\section{Validation}

The fators identified using the approach described above may predict the patient response to sivelestat or may represent independent prognostic indicators. To investigate this, we conducted a validation study in the absence of sivelestat. Patients who were using a medical ventilator but were not administered sivelestat were enrolled in Kanetsu hospital from January 2013 to December 2014. We excluded perioperative patients and those who had been hospitalized for $<24 \mathrm{~h}$ from this study.

Patients were divided into two groups, depending on whether they were weaned from the ventilator within 28 days (the weaning group) or not (the no weaning group).

These groups were compared using the approach described in Study design.

\section{Statistics}

We used statistical analyses to investigate which factors predicted the therapeutic effect of sivelestat. We performed an $F$-test to determine whether each factor exhibited a homoscedastic distribution. A $t$-test was used in the initial screening of the effective and ineffective groups if the distribution showed homoscedasticity; if not, Welch's $t$-test was used. The numbers of male patients, sepsis, and DIC in the two groups were analyzed

Table 1 Profiles of the patients included in the case-control study

\begin{tabular}{|c|c|c|c|}
\hline & $\begin{array}{l}\text { Effective group } \\
(n=28)\end{array}$ & $\begin{array}{l}\text { Ineffective group } \\
(n=25)\end{array}$ & $P$ \\
\hline$\overline{\text { Age(yr) }}$ & $67.7 \pm 14.5$ & $77.0 \pm 8.4$ & $0.006^{b}$ \\
\hline Male (\%) & $21(75.0 \%)$ & $20(80.0 \%)$ & $0.664^{c}$ \\
\hline Sepsis (\%) & $8(28.6 \%)$ & $13(52.0 \%)$ & $0.082^{c}$ \\
\hline DIC (\%) & $9(32.1 \%)$ & $11(44.0 \%)$ & $0.374^{c}$ \\
\hline $\mathrm{ALT}(\mathrm{IU} / \mathrm{L})$ & $46.8 \pm 38.9$ & $29.3 \pm 26.4$ & $0.064^{a}$ \\
\hline AST(IU/L) & $67.3 \pm 61.9$ & $75.1 \pm 119.1$ & $0.772^{b}$ \\
\hline $\mathrm{LDH}(\mathrm{IU} / \mathrm{L})$ & $569 \pm 222$ & $670 \pm 744$ & $0.350^{b}$ \\
\hline ALP(IU/L) & $306 \pm 160$ & $500 \pm 829$ & $0.315^{b}$ \\
\hline$\gamma$-GTP(IU/L) & $68.9 \pm 80.2$ & $40.2 \pm 34.6$ & $0.121^{b}$ \\
\hline $\mathrm{BUN}(\mathrm{mg} / \mathrm{dL})$ & $31.9 \pm 20.8$ & $37.3 \pm 21.6$ & $0.353^{a}$ \\
\hline $\mathrm{Scr}(\mathrm{mg} / \mathrm{dL})$ & $2.0 \pm 2.7$ & $2.1 \pm 2.6$ & $0.961^{\mathrm{a}}$ \\
\hline $\mathrm{RBC}\left(\times 10^{4} / \mu \mathrm{L}\right)$ & $376.1 \pm 84.9$ & $327.2 \pm 72.1$ & $0.029^{a}$ \\
\hline$W B C(/ \mu L)$ & $11,121 \pm 7299$ & $13,441 \pm 8549$ & $0.292^{a}$ \\
\hline Neut(\%) & $88.4 \pm 9.3$ & $85.9 \pm 10.3$ & $0.607^{a}$ \\
\hline $\operatorname{Plt}\left(\times 10^{4} / \mu \mathrm{L}\right)$ & $18.8 \pm 9.8$ & $16.0 \pm 9.8$ & $0.295^{a}$ \\
\hline Alb(g/dL) & $3.1 \pm 2.0$ & $2.4 \pm 0.6$ & $0.127^{b}$ \\
\hline $\mathrm{CRP}(\mathrm{mg} / \mathrm{dL})$ & $19.6 \pm 11.2$ & $15.5 \pm 9.4$ & $0.168^{a}$ \\
\hline$\left[\mathrm{H}^{+}\right]\left(\times 10^{-8}\right)$ & $3.639 \pm 0.667$ & $4.422 \pm 0.936$ & $0.001^{b}$ \\
\hline $\mathrm{PO}_{2}(\mathrm{mmHg})$ & $93.2 \pm 48.1$ & $61.4 \pm 24.7$ & $0.004^{b}$ \\
\hline $\mathrm{PCO}_{2}(\mathrm{mmHg})$ & $36.6 \pm 9.3$ & $47.7 \pm 17.5$ & $0.007^{b}$ \\
\hline Dose(mg/kg/h) & $0.216 \pm 0.049$ & $0.209 \pm 0.046$ & $0.785^{a}$ \\
\hline
\end{tabular}

The data were expressed as the mean \pm standard deviation, except for the number of males, sepsis, and DIC. The value of $\left[\mathrm{H}^{+}\right]$was calculated as follows: $\left[\mathrm{H}^{+}\right]=10^{-\mathrm{pH}}$

a: Student $t$-test, b: Welch's $t$-test, c: Chi-square test 
using the Chi-square test. We then performed multivariate logistic regression analysis (stepwise: likelihood ratio) using SPSS ${ }^{\bullet}$ (SPSS Inc., Chicago, USA) to identify factors that showed a significant association with a high mechanical ventilation weaning rate. We employed the stepwise method because the method is suitable to control confounding factors in multivariate logistic regression analysis.

\section{Results}

\section{Case-control study}

The profiles of the effective $(n=28)$ and ineffective $(n=25)$ patient groups are shown in Table 1. The age, hydrogen ion concentration $\left(\left[\mathrm{H}^{+}\right]\right)$, and $\mathrm{PCO}_{2}$ values were significantly lower in the effective group than in the ineffective group. In contrast, the red blood cell count (RBC) and $\mathrm{PO}_{2}$ were significantly higher in the effective group than in the ineffective group. Other factors showed no statistically significant differences between these groups.

We used the factors that differed significantly between these study groups (age, $\mathrm{RBC},\left[\mathrm{H}^{+}\right], \mathrm{PO}_{2}$, and $\mathrm{PCO}_{2}$ ) to perform multivariate logistic regression analysis. The relationships between these factors are shown in Fig. 1. The value of $\mathrm{PO}_{2}$ slightly correlated with that of $\left[\mathrm{H}^{+}\right]$.
The results of the multivariate logistic regression analysis are shown in Table 2.

Age and $\mathrm{PCO}_{2}$, which correlated with $\left[\mathrm{H}^{+}\right]$and/or $\mathrm{PO}_{2}$, were dropped from the process. Three factors $\left(\mathrm{RBC},\left[\mathrm{H}^{+}\right]\right.$, and $\mathrm{PO}_{2}$ ) were therefore identified as candidates for the prediction of the therapeutic effect of sivelestat.

\section{Validation}

The validation study included 105 patients receiving medical ventilation in the absence of sivelestat in Kan-etsu hospital from January 2013 to December 2014. The patient's age, sex, $\mathrm{RBC}$, and $\left[\mathrm{H}^{+}\right]$values in these weaning and no weaning groups are shown in Table 3 . The $\left[\mathrm{H}^{+}\right]$value was significantly higher in the no weaning ventilator group than in the weaning group $(P=0.006)$ and there was no significant difference in $\mathrm{RBC}$ between these groups $(P=0.13)$.

\section{Discussion}

Although the efficacy and safety of Sivelestat in the Japanese patients was demonstrated in the phase III double-blind study and the postparket study, the difference in the 28-day ventilator-weaning rate was only $13 \%$ between the sivelestat and control group in the postparket study and the negative results was reported

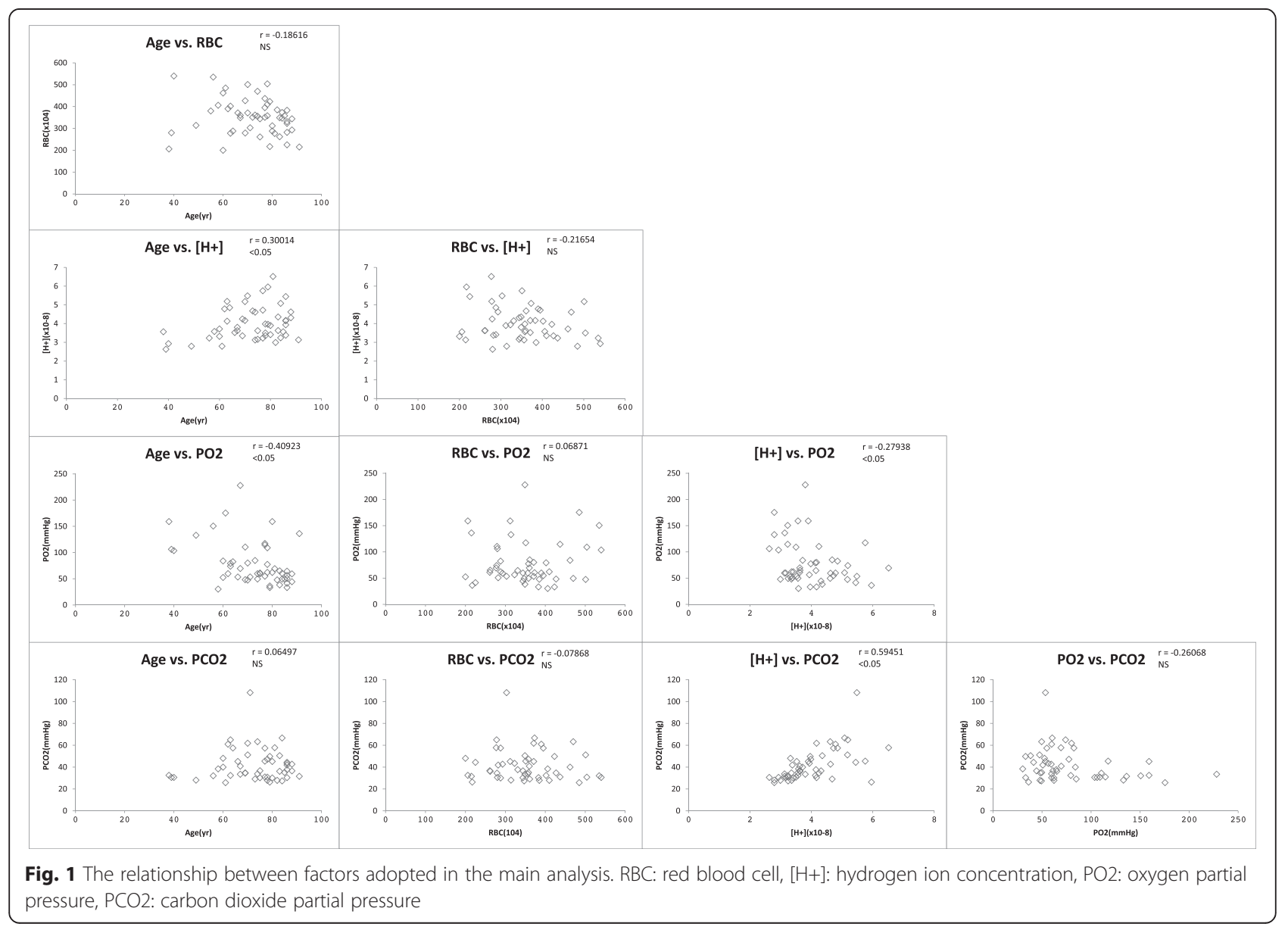


Table 2 Logistic regression analysis

\begin{tabular}{lrllll}
\hline & \multicolumn{1}{c}{ B } & S.E. & $p$-value & AOR & $95 \% \mathrm{Cl}$ \\
\hline $\mathrm{RBC}$ & 0.012 & 0.006 & 0.044 & 1.012 & $1.000-1.024$ \\
{$\left[\mathrm{H}^{+}\right]$} & -1.194 & 0.510 & 0.019 & 0.303 & $0.112-0.824$ \\
$\mathrm{PO}_{2}$ & 0.030 & 0.014 & 0.031 & 1.030 & $1.003-1.058$ \\
constant & -1.412 & 2.856 & 0.621 & & \\
\hline
\end{tabular}

$B$ regression coefficient

S.E. standard error

$A O R$ adjusted odds ratio

$95 \%$ Cl $95 \%$ confidence interval

in the STRIVE study $[4,15,16]$. The reason why the efficacy was small or negative would be the presence of the responder and non-responder. Thus, we attempted to identify factors predicting the therapeutic effects of sivelestat. This case-control study is the first trial to find predictors of the therapeutic effect of sivelestat in patients with ALI associated with SIRS.

We initially evaluated the differences between the effective (ventilator weaning) and ineffective groups of patients who were administered with sivelestat. This logistic regression analysis revealed that three factors, $\left[\mathrm{H}^{+}\right], \mathrm{RBC}$, and $\mathrm{PO}_{2}$, were significantly associated with the mechanical ventilation weaning rate of these patients.

A predictive formula was developed:

$$
\begin{aligned}
\ln (\mathrm{y} / 1-\mathrm{y})= & 0.012 \times \mathrm{RBC}-1.194 \times\left[\mathrm{H}^{+}\right] \\
& +0.030 \times \mathrm{PO}_{2}-1.412
\end{aligned}
$$

where $y$ was the probability of a good response to sivelestat. According to this formula, a higher $\mathrm{RBC}$, lower $\left[\mathrm{H}^{+}\right]$, and higher $\mathrm{PO}_{2}$ were associated with a greater probability of a good therapeutic response to sivelestat.

Formula 1 allows calculation of the probability of sivelestat effectiveness in a patient using the values of these predictive factors. The normal reference values for $\left[\mathrm{H}^{+}\right]$, $\mathrm{RBC}$, and $\mathrm{PO}_{2}$ are $3.548 \times 10^{-8}$ (corresponding to a $\mathrm{pH}$ of 7.45$), 450\left(\times 10^{4} / \mu \mathrm{L}\right)$, and 100 , respectively. Substitution of these reference values into formula 1 produces a probability of $94 \%$. If one of these factors $\left(\left[\mathrm{H}^{+}\right], \mathrm{RBC}\right.$, or $\left.\mathrm{PO}_{2}\right)$ changed to $5.853 \times 10^{-8}(\mathrm{pH}=7.23), 221$, or 8.3 , respectively, the probability was reduced to $50 \%$.

This indicated that $\mathrm{PO}_{2}$ was unlikely to modulate the patient response to sivelestat significantly, because a $\mathrm{PO}_{2}$ value of 8.3 is not realistic in the clinical situation.
On the other hand, $\left[\mathrm{H}^{+}\right]$and $\mathrm{RBC}$ may have greater effect on sivelestat response because a $\left[\mathrm{H}^{+}\right]$value of $5.853 \times 10^{-8}$ $(\mathrm{pH}=7.23)$, or a $\mathrm{RBC}$ value of 221 are often observed in hospitalized patients.

Respiratory failure induces severe acidosis, where pulmonary $\mathrm{CO}_{2}$ elimination decreases (respiratory acidosis) and/or an oxygen deficit (lactic acidosis) occurs. Our findings suggested that as respiratory function declined, sivelestat became less effective. Red blood cells transport oxygen within the body and a reduced RBC therefore indicates oxygen deficiency, which necessitates a longer ventilation period.

Although we found two candidate predictive factors in the first study, it was possible that these predicted ventilator weaning, regardless of sivelestat administration. Thus, we conducted a validation study of $\left[\mathrm{H}^{+}\right]$and $\mathrm{RBC}$ values in patients who did not receive sivelestat.

The mean $[\mathrm{H}+]$ value was significantly higher in the no weaning group, as compared with the weaning group, indicating that this parameter predicted ventilator weaning, even in the absence of sivelestat. On the other hand, $\mathrm{RBC}$ showed little effect on the weaning rate of these patients, indicating that only $\mathrm{RBC}$ predicted the therapeutic effect of sivelestat.

Patients who received dialysis therapy were expected to have variable $\mathrm{RBC}$ values. Then, we count number of dialyzing patients in the case-control study. The numbers of dialyzing patients were 8 in the effective group and 6 in the ineffective group. The ratio of the dialyzing patients was not significantly different between the groups (chi-square test, $p=0.706$ ).

Because a few patients were administered sivelestat in Kan-etsu hospital, the patient numbers of effective and ineffective group were 28 and 25, respectively. Such small sample size is limitation of this study. The study of large sample size is needed.

\section{Conclusion}

Evaluated $\left[\mathrm{H}^{+}\right], \mathrm{RBC}$ and $\mathrm{PO}_{2}$ levels prior to sivelestat administration predicted that it would produce less therapeutic benefit. The RBC represented a particularly valuable predictor of this therapeutic effect. ALI patients with high $\mathrm{RBC}$ levels may be the best candidates for sivelestat administration.

Table 3 Profiles of the patients included in the validation study

\begin{tabular}{lllll}
\hline & & Weaning ventilator group $(n=56)$ & Non weaning ventilator group $(n=49)$ & $P$ \\
\hline Basical data & Age $(\mathrm{yr})$ & $77.5 \pm 14.0$ & $79.1 \pm 9.8$ & $0.521^{\mathrm{b}}$ \\
& Male $(\%)$ & $29(51.8 \%)$ & $35(71.4 \%)$ & $0.040^{c}$ \\
Candidates & $\mathrm{RBC}\left(\times 10^{4} / \mu \mathrm{L}\right)$ & $385.6 \pm 72.9$ & $361.7 \pm 91.2$ & $0.139^{\text {a }}$ \\
& {$\left[\mathrm{H}^{+}\right]\left(\times 10^{-8}\right)$} & $4.661 \pm 1.534$ & $6.158 \pm 3.418$ & $0.006^{\mathrm{b}}$ \\
\hline
\end{tabular}

The data were expressed as the mean \pm standard deviation, except for the number of males

The value of $\left[\mathrm{H}^{+}\right]$was calculated as follows: $\left[\mathrm{H}^{+}\right]=10^{-\mathrm{pH}}$

a: Student $t$-test, b: Welch's $t$-test, c: Chi-square test 


\section{Abbreviations}

ALI, acute lung injury; NE, neutrophil elastase; SIRS, systemic inflammatory response syndrome; STRIVE, Sivelestat Trial in ALI Patients Requiring Mechanical Ventilation; VFD, ventilator-free days

\section{Authors' contributions}

TO collected the data, performed the statistical analysis, and drafted the manuscript. NY conceived of the study and participated in its design and coordination. KM participated in the design of study and completed the manuscript. All authors read and approved the final manuscript.

\section{Competing interests}

The authors declare that they have no competing interests.

\section{Author details}

'Department of Pharmacy, Kan-etsu Hospital, 145-1 Suneori, Tsuruashima-shi, Saitama 350-2213, Japan. ${ }^{2}$ Research Center for Clinical Pharmacy, Faculty of Pharmacy, Musashino University, 1-1-20 Shinmachi, Nishitokyo-shi, Tokyo 202-8585, Japan

Received: 17 February 2016 Accepted: 1 July 2016

Published online: 24 August 2016

\section{References}

1. Kawabata K, Suzuki M, Sugitani M, Imaki K, Toda M, Miyamoto T. ONO-5046, a novel inhibitor of human neutrophil elastase. Biochem Biophys Res Commun. 1991;177:814-20.

2. Kawabata K, Hagio T, Matsuoka S. The role of neutrophil elastase in acute lung injury. Eur J Pharmacol. 2002;451:1-10.

3. Kodama T, Yukioka H, Kato T, Kato N, Hato F, Kitagawa S. Neutrophil elastase as a predictive factor for development of acute lung injury. Intern Med. 2007;46:699-704.

4. Aikawa $N$, Ishizaka A, Hirasawa $H$, Shimazaki S, Yamamoto $Y$, Sugimoto $H$, et al. Reevaluation of the efficacy and safety of the neutrophil elastase inhibitor, Sivelestat, for the treatment of acute lung injury associated with systemic inflammatory response syndrome; a phase IV study. Pulm Pharmacol Ther. 2011:24:549-54.

5. Nakayama Y, Odagaki Y, Fujita S, Matsuka S, Hamanaka N, Nakai H, et al. Clarification of mechanism of human sputum elastase inhibition by a new inhibitor, ONO-5046, using electrospray ionization mass spectrometry. Bioorg Med Chem Lett. 2002;12:2349-53.

6. Feng L, Zhu W, Huang C, Li Y. Direct interaction of ONO-5046 with human neutrophil elastase through ${ }^{1} \mathrm{H}$ NMR and molecular docking. Int J Biol Macromol. 2012:51:196-200.

7. Amemori H, Maeda Y, Torikai A, Nakashima M. Sivelestat relaxes vascular smooth muscle contraction in human gastric arteries. J Physiol Biochem. 2011;67:589-93.

8. Nagai $Y$, Watanabe M, Baba Y, Iwatsuki M, Hirashima K, Karashima R, et al. Preventive effect of sivelestat on postoperative respiratory dusorders after thoracic esophagectomy. Surg Today. 2013:43:361-6.

9. Nishijima J, Matsuda M, Ando S, Hirasawa M, Suzuki T, Makuuchi H. The effects of the early administration of sivelestat sodium, a selective neutrophil elastase inhibitor, on the postoperative course after radical surgery for esophageal cancer. Surg Today. 2012;42:659-65.

10. Mimatsu K, Oida T, Kawasaki A, Kano H, Kuboi Y, Amano S. Influence of neutrophil elastase inhibitor on the postoperative couse in patients with esophageal cancer after transthoracic esophagectomy. Hepatogastroenterology. 2011;58:1583-7.

11. Yamaguchi K, Sugasawa $Y$, Takeuchi K, Kugimiya T, Kumakura S, Iwanuma $Y$ et al. Effects of sivelestat on bronchial inflammatory responses after esophagectomy. Int J Mol Med. 2011;28:187-92.

12. Makino H, Kunisaki C, Kosaka T, Akiyama H, Morita S, Endo I. Perioperative use of a neutrophil elastase inhibitor in video-assisted thoracoscopic oesophagectomy for cancer. Br J Surg. 2011;98:975-82.

13. Inoue N, Oka N, Kitamura T, Tomoyasu T, Miyaji K. Neutrophil elastase inhibitor sivelestat attenuates perioperative inflamattory response in pediatric heart surgery with cardiopulmonary bypass. Int Heart J. 2013:54:149-53.

14. Morimoto K, Nishimura K, Miyasaka S, Maeta H, Taniguchi I. The effect of sivelestat sodium hydrate on severe respiratory failure after thoracic aortic surgery with deep hypothermia. Ann Thorac Cardiovasc Surg. 2011;17:369-75.
15. Zeiher BG, Artigas A, Vincent JL, Dmitrienko A, Jackson K, Thompson BT, Bernard G, STRIVE Study Group. Neutrophil elastase inhibition in acute lung injury: results of the STRIVE study. Crit Care Med. 2004;32:1695-702.

16. Tamakuma S, Ogawa M, Aikawa N, Kubota T, Hirasawa H, Ishizaka A Taenaka N, Hamada C, Matsuoka S, Abiru T. Relationship between neutrophil elastase and acute lung injury in humans. Pulm Pharmacol Ther. 2004; 17:271-9.

\section{Submit your next manuscript to BioMed Central and we will help you at every step:}

- We accept pre-submission inquiries

- Our selector tool helps you to find the most relevant journal

- We provide round the clock customer support

- Convenient online submission

- Thorough peer review

- Inclusion in PubMed and all major indexing services

- Maximum visibility for your research

Submit your manuscript at www.biomedcentral.com/submit
Biomed Central 